\title{
A Tensile Split Hopkinson Bar for Testing Particulate Polymer Composites Under Elevated Rates of Loading
}

\author{
A.T. Owens $\cdot$ H.V. Tippur
}

Received: 3 March 2008 / Accepted: 30 September 2008 / Published online: 26 November 2008

(C) Society for Experimental Mechanics 2008

\begin{abstract}
A tensile split Hopkinson bar apparatus is developed for testing high strain rate behavior of glass-filled epoxy. The apparatus uses a specimen gripping configuration which does not require fastening and/or gluing and can be readily used for castable materials. Details of the experimental setup, design of grips and specimen, specimen preparation method, benchmark experiments, and tensile responses are reported. Also, the effects of filler volume fraction (0-30\%) and particle size $(11-42 \mu \mathrm{m})$ are examined under high rates of loading and the results are compared with the ones obtained from quasi-static loading conditions. The results indicate that the increase in the loading rate contributes to a stiffer and brittle material response. In the dynamic case lower ultimate stresses are seen with higher volume fractions of filler whereas in the corresponding quasi-static cases an opposite trend exists. However, the absorbed specific energy values show a decreasing trend in both situations. The results are also evaluated relative to the existing micromechanical models. The tensile response for different filler sizes at a constant volume fraction $(10 \%)$ is also reported. Larger size filler particles cause a reduction in specimen failure stress and specific energy absorbed under elevated rates of loading. In the quasi-static case, however, the ultimate stress is minimally affected by the filler size.
\end{abstract}

Keywords Particulate composites .

Tensile stress-strain response $\cdot$ High-strain rate failure .

Microstructural effects · Split Hopkinson bar

A.T. Owens $\cdot$ H. Tippur $(\bowtie$, SEM member $)$

Department of Mechanical Engineering, Auburn University,

Auburn, AL 36849, USA

e-mail: htippur@eng.auburn.edu

A.T. Owens

AMRDEC, US Army RDECOM,

Redstone Arsenal, AL, USA

\section{Introduction}

Polymer composites have gained increasing popularity in recent years finding wide ranging applications. The electronics industry, for example, makes use of particle filled composites as underfill materials. In this case, ball grid arrays, chip scale packages, and flip chip on board assemblies use epoxies filled with silica or some other type of particle to improve reliability as well as to provide environmental protection for solder joints. These materials may be used to carry mechanical loads as well as to enhance thermal performance. Syntactic foams are another common type of particulate composite where hollow glass microspheres are dispersed in a polymer. These materials exhibit excellent compressive properties for undersea applications, and their density and thermal properties make them attractive for certain aerospace and military applications. The automotive industry also uses many types of filled plastics, such as particle reinforced acrylonitrile butadiene styrene (ABS). In dentistry, particulate composites are commonly used as restoratives and fillers. For example, ground glass particles are mixed into a BIS-GMA matrix to create a durable filling. Bone cement, commonly used in orthopedic surgery, is another example of a filled polymer where a polymeric powder is mixed with a liquid monomer. When the monomer polymerizes, a matrix is formed with interspersed polymer spheres.

In view of this growing popularity, there is a need to understand the deformation behavior of these material systems across a broad range of strain rates. In general, engineering structures are subject to a vast array of loading conditions, and in particular, loading rates can vary from being almost static to highly transient. In the lower extreme, there is creep loading, where the strain in a material changes with time under a constant load. In the upper extreme, there is shock loading, where strain rates may 
exceed $1 \times 10^{9} \mathrm{~s}^{-1}$. It has been demonstrated that the mechanical behavior, specifically stress-strain response and failure mechanisms, of the material constituents of engineering structures can vary widely depending on the loading rate. Thus, it is necessary to characterize these materials under loading rates of the same order of magnitude as those that the material will see in service.

Research has been conducted for understanding the quasi-static behavior of particle filled polymers and is well documented in the literature. For instance, Ishai and Cohen $[1,2]$ have carried out experiments involving a polymer filled with glass particles and documented the stiffening effect of the glass particle fillers. They also noted an increase in peak specimen stress with an increase in filler particle volume fraction under quasi-static loading. Also, a fair amount of work has been accomplished in the area of fracture mechanics of glass-filled epoxy composites. Spanoudakis and Young [3] studied both the effects of particle size as well as volume fraction on fracture properties. Nakamura and Yamaguchi [4] studied particle size effect on fracture properties as well. The fracture toughness and energy released rate both increased with particle size. More recently, Kitey and Tippur [5] have performed optical measurements to study the role of microstructure in a dynamically growing crack in a particle filled epoxy system. Their work showed that glass fillers improved the steady state fracture toughness of the epoxy and that there was a specific particle size for optimum fracture toughness. Crack tip blunting due to particle interfaces as well as crack front twisting served as toughening mechanisms for the filled systems.

In terms of higher strain rate loading, Chen and coworkers have investigated the quasi-static tensile and compressive behavior with the dynamic tensile and compressive behavior of two unfilled thermosetting polymers [6]. They observed that the materials exhibited markedly different responses under dynamic tension as opposed to dynamic compression. They also have studied the temperature effects [7] and confinement effects [8] for syntactic foams under dynamic compressive loading. In the study of temperature effects [7], it was observed that there was very little adiabatic temperature rise in the specimen while it was undergoing dynamic compressive loading. However, environmental temperature changes had a complex effect on material behavior. The material softened with increasing temperature above the transition and also with decreasing temperature below the transition. In the study of lateral confinement effects [8], the specimens failed in an elastic-plastic-like behavior whereas they had failed in an elastic-brittle fashion under uniaxial tensile loading. Several other researchers have studied soft materials using the split Hopkinson bar including Gray et al. [9], who studied Adiprene L-100 rubber. This material exhibited a very high sensitivity to strain rate.
The primary goal of the present work is to gain understanding of the stress-strain response of a glass-filled epoxy system under dynamic tensile loading conditions using a split Hopkinson bar (SHB) apparatus. This can be valuable in understanding dynamic fracture behavior as well as for simulating mode-I failure computationally.

This paper outlines the development of the experimental setup used to accomplish these goals along with some of the underlying details including specimen grip and specimen design, and specimen preparation. The outcome of a set of calibration experiments is then shown to demonstrate the capability of the setup. Next, the results of a study of filler particle volume fraction effect on the stress-strain response of filled polymers are presented and compared with various empirical models. Finally, the results of a study of filler particle size effect are shown in an effort to understand the role of particle size on the stress-strain response of the polymer.

\section{Experimental Setup}

The Hopkinson bar has been one of the most prominent methods used for dynamic material characterization since its introduction. This technique, first introduced by Hopkinson [10] in 1914 and later modified to utilize the split bar concept by Kolsky [11] in 1949, has been used widely for compression, tension, and shear testing. The basic working principle of the method is that an impact occurs on one end of a long bar. This produces a loading pulse that propagates the length of the incident bar, loads the specimen, and then propagates along the transmitter bar. At the incident bar-specimen interface, part of the loading pulse is reflected back down the incident bar. The strain histories of the incident, reflected, and transmitted pulses can be recorded and used to deduce the stress, strain, and strain rate of the specimen.

Since the split Hopkinson pressure bar was first adapted for tensile loading, extensive research has been completed to study a wide variety of problems. Many configurations have been developed for generating tensile loading pulses including those by Lindholm and Yeakley [12], Nicholas [13], and Staab and Gilat [14]. A setup that uses a hollow striker that slides along the incident bar and impacts an anvil to produce the tensile load is used by Ogawa [15] to study the dynamic Baushinger effect in materials. A similar set up is used by Huh et al. [16] to study the dynamic behavior of automotive sheet metals. Recently, Mohr and Gary [17] have developed a novel M-shaped specimen for high-strain rate tensile testing of aluminum alloys.

The setup developed for this work uses the reverse impact concept that uses a hollow striker riding along the incident bar to produce the tensile load (see Fig. 1). The striker, a 254-mm long tube with a 25.4-mm outside 
diameter and a $12.5-\mathrm{mm}$ bore, is accelerated by releasing the air pressure in the gas gun chamber. This translates along a 2.4-m long incident bar which passes through the barrel of the gas gun. The loading pulse is produced when the striker impacts a small anvil on the end of the incident bar. This anvil is registered against a rubber pad to provide damping. The duration of the loading pulse is controlled by the length of the striker, $S$. The time can be computed as the time it requires an elastic wave to propagate one round trip in the striker, or $t=2 S / C_{0}$ where $C_{0}$ is the bar wave speed of the striker material. The amplitude of the loading pulse is related to the velocity of the striker, $V_{\mathrm{S}}$. The striker, anvil, and incident/transmitter bars are all constructed from 7075T651 aluminum alloy. (The elastic impedance of the aluminum bars is closer to that of the polymeric specimens than the elastic impedance of more commonly used steel bars. This improves the transmissivity of the elastic waves across the interfaces between the specimen and the bars.)

For this setup, strain gages are mounted approximately $0.75 \mathrm{~m}$ from the specimen end of both the incident and transmitter bars of equal length. Favorable locations for the strain gages can be found by plotting the positions of the elastic waves in $X-t$ space (Fig. 2). The strain gages must be located close enough to the interface that the signal measured by the gage is an accurate representation of the signal as it reaches the specimen. However, superposition of the incident and reflected pulses must be avoided. The gage location in the current setup satisfies both of these requirements.

The recorded signals are used to compute the specimen strain rate, strain, and stress using the equations below:

$\frac{\partial \varepsilon}{\partial t}=-\frac{2 C_{0} \varepsilon_{\mathrm{R}}(t)}{L}$

$\varepsilon(t)=-\frac{2 C_{0}}{L} \int \varepsilon_{\mathrm{R}}(t) \mathrm{d} t$,

$\sigma(t)=\frac{E A_{\mathrm{B}}}{A_{\mathrm{S}}} \varepsilon_{\mathrm{T}}(t)$.

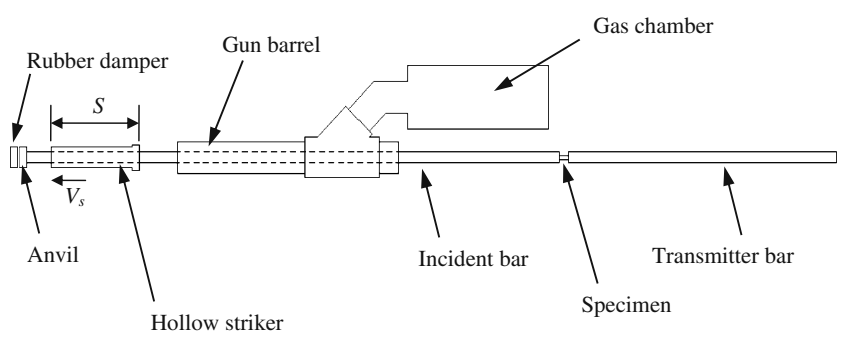

Fig. 1 Schematic of experimental apparatus

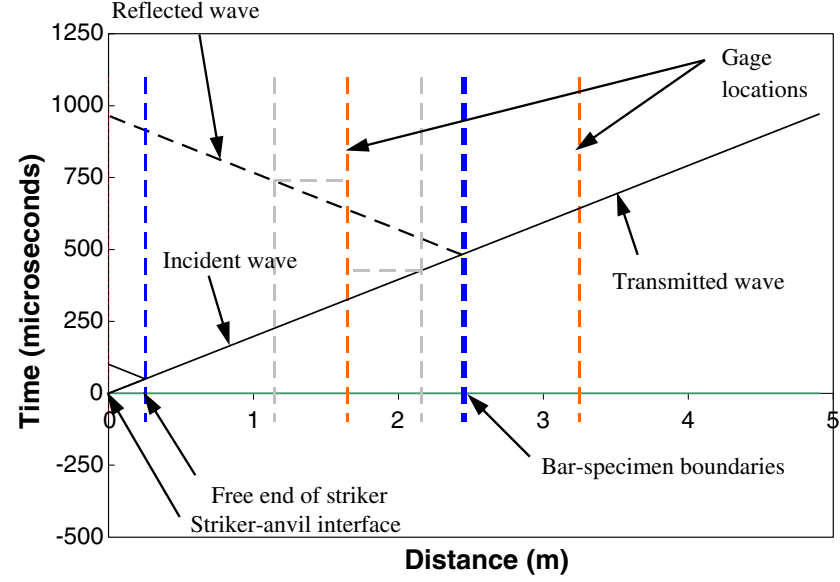

Fig. 2 Lagrangian $X-t$ diagram

In the above equations, $\sigma$ and $\varepsilon$ denote stress and strain respectively and both are functions of time, $t$. Subscripts $\mathrm{R}$ and $\mathrm{T}$ are used to denote reflected and transmitted signals, $L$ is the specimen gage length, and $C_{0}$ denotes the bar wave speed. In equation (3), $E$ is the elastic modulus of the bar, $A_{\mathrm{B}}$ is the cross-sectional area of the bar, and $A_{\mathrm{S}}$ is the crosssectional area of the specimen. A typical set of signals is shown in Fig. 3. Due to the design of this setup and strain gage location, there is a short duration of time, after the loading event, where the incident and reflected signals are overlapped. For this reason, the reflected signal is only used to estimate equilibrium. The incident and transmitted signals are used to calculate strain rate. This is possible since it is assumed that $\varepsilon_{\mathrm{R}}=\varepsilon_{\mathrm{T}}-\varepsilon_{\mathrm{I}}$ where I denotes incident signal.

The test specimen is mounted between the incident and transmitter bars by means of a dovetail-shaped grip. This allows the use of a dogbone-shaped specimen geometry instead of one of the more commonly used threaded or bonded configurations. Dogbone-shaped specimens have been widely used and have known value in quasi-static tensile testing. This geometry also permits castable specimens,

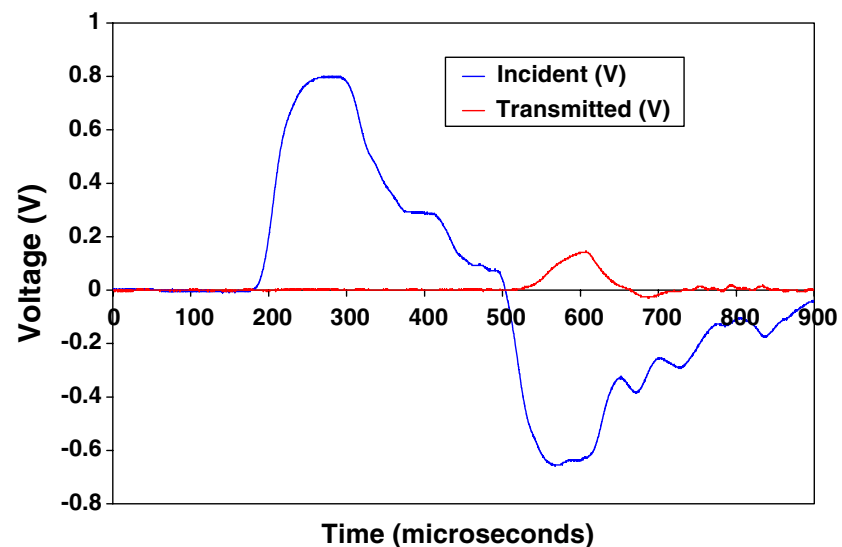

Fig. 3 Typical incident, reflected, and transmitted strain histories 
Fig. 4 (a) Dovetail specimen geometry, (b) resulting stress distribution on a quarter model arrived at iteratively using finite element analysis, (c) key specimen dimensions (a)

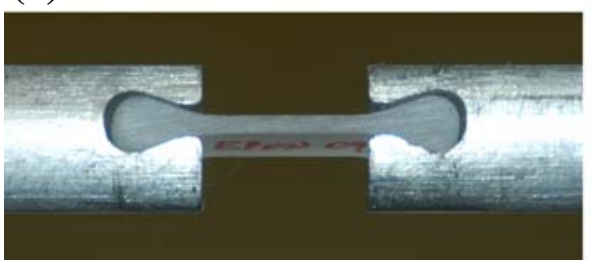

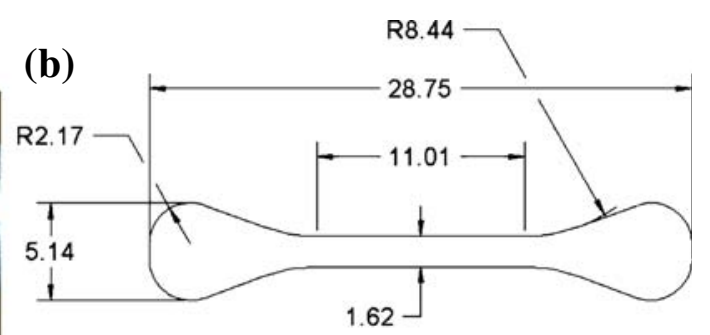

reducing preprocessing time and difficulty. In this configuration, it is important that the setup be slightly pre-tensioned in the loading direction. Thus the load in the specimen begins to increase immediately after the arrival of the stress wave at the interface. This also avoids the necessity of bonding the specimen between the bars. The shape and size of the specimen is shown in Fig. 4(a) and (b). Figure 4(a) shows the specimen mounted in the apparatus as it is mounted in an actual test. Figure 4(b) shows the specimen dimensions. Several design iterations were made to arrive at a shape that has uniform stresses in the gage section [18]. Some of the relevant details regarding grip and specimen design are provided in Appendix A. By introducing a large radius between the gage section and the grips, the stress concentration is minimized. Also, the grip section is much larger than the gage section, thus reducing the amount of strain in the grip. This is important because strain equations are derived based on bar end displacements. Appreciable amounts of strain in the grip section would invalidate the equations for specimen strain rate and strain.

\section{Test Specimens}

EPON ${ }^{\mathrm{TM}}$ 828, manufactured by HEXION ${ }^{\mathrm{TM}}$ Specialty Chemicals, was used as the matrix material for the current work. This is a popular epoxy system with applications ranging from fiber reinforced composites to aerospace adhesives. The hardening agent, EPIKURE ${ }^{\mathrm{TM}} 3233$, is a T403-type amine-based curing agent. The epoxy was filled with SPHERIGLASS ${ }^{\circledR}$ glass microspheres manufactured by Potters Industries Inc.

The dogbone shaped specimens were produced by a casting process, depicted in Fig. 5(a)-(d). Master specimens [Fig. 5(a)] were first machined from solid steel using electrical discharge machining (EDM) to ensure the intricate shape was cut precisely. Next a mold cavity was produced by creating a barrier and pouring silicone rubber (PlatSil ${ }^{\circledR} 73$ Series from PolyTek Development Corporation) around the master specimen to create a negative of the specimen [Fig. 5(a), (b)]. This is a very flexible rubber mold material with low shrinkage, resulting in very good dimensional stability of the mold. After the rubber is cured, the steel masters were removed from the mold leaving behind cavities suitable for casting epoxy or glass-filled epoxy specimens [Fig. 5(c), (d)].

For the glass-filled epoxy test specimens, the general preparation sequence was as follows. First, the desired quantities of resin and glass particles were measured out and placed into an oven at $50^{\circ} \mathrm{C}$ for $1 \mathrm{~h}$ in order to lower the viscosity of the resin. This also allowed the particles to release any trapped moisture. Next, the particles were mixed into the resin and placed back into the oven at $50^{\circ} \mathrm{C}$ for another $2 \mathrm{~h}$. This allowed the mixture to degas while the resin remained at a relatively low viscosity. While continuing to maintain the temperature of the mixture at $50^{\circ} \mathrm{C}$, the curing agent was slowly stirred into the mixture. After pouring the mixture into the mold, the mold was placed in a vacuum chamber (approximately $-85 \mathrm{kPa}$ gage). Periodically, air bubbles were skimmed from the tops of the molds and the mixing container. This ensured full degassing of the mixture. All castings were allowed to cure at room temperature for $24 \mathrm{~h}$ prior to being placed in an oven for the heated cure cycle. The cure cycle ramped from $25^{\circ} \mathrm{C}$ to $80^{\circ} \mathrm{C}$ at a rate of $2^{\circ} \mathrm{C} / \mathrm{min}$. The temperature was then held at $80^{\circ} \mathrm{C}$ for $2.5 \mathrm{~h}$ prior to returning to room temperature at a rate of about $2^{\circ} \mathrm{C} / \mathrm{min}$. Upon completion of the curing cycle, the specimens were finished to final dimensions using a bench router.

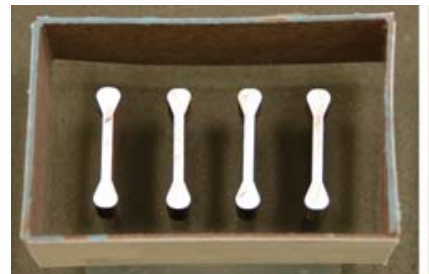

(a)

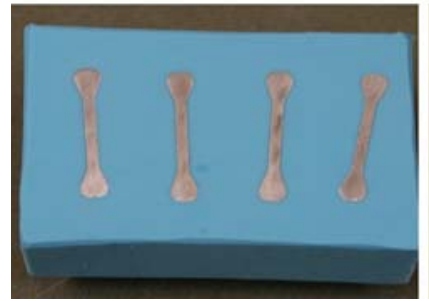

(c)

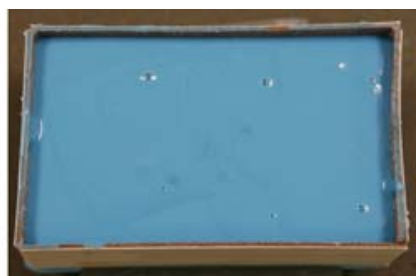

(b)

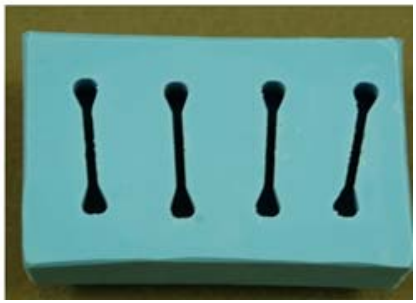

(d)
Fig. 5 Mold fabrication process: (a) steel master specimens with cardboard barrier on glass substrate, (b) silicone rubber casting, (c) cured casting prior to removal of steel masters, (d) resultant mold cavity (overall specimen length $=28.75 \mathrm{~mm}$ ) 


\section{Calibration Experiments}

Specimen Equilibrium

For high strain rate testing, care has to be taken to ensure that the testing conditions are valid. One of the major criteria for this is that the specimen is in a state of dynamic equilibrium during the test. The equilibrium state is determined by comparing the stresses at each end of the gage section of the specimen.

The common way to check the equilibrium conditions for a split Hopkinson bar specimen is by comparing the stresses on the incident and transmitter ends of the specimen. This is done by calculating the specimen stress directly using the measured transmitted wave, and comparing this with the stresses found using the computed transmitted wave, $\varepsilon_{\mathrm{T}}=$ $\varepsilon_{\mathrm{I}}+\varepsilon_{\mathrm{R}}$ where subscripts T, R, I denote transmitted, reflected and incident signals, respectively. Given that it takes approximately three reverberations of an elastic wave in the specimen to reach equilibrium [19], and also that the specimens have a gage length of $11 \mathrm{~mm}$ and an elastic wave speed of approximately $2,500 \mathrm{~m} / \mathrm{s}$, it should require approximately $25 \mu \mathrm{s}$ for the specimen to reach equilibrium in the gage section. This is validated in Fig. 6. Evidently, the percentage difference between the incident and transmitted signals are approximately $10 \%$ of each other after about $25 \mu \mathrm{s}$, suggesting that the sample is approximately in equilibrium during this time window.

\section{Benchmarking of the Set Up}

Due to the nature of high strain rate testing, SHB setups are often tailored for specific materials or types of materials. Thus, it is often difficult to obtain data for accurate comparison to a given setup unless comparisons are being made with identical materials obtained from identical

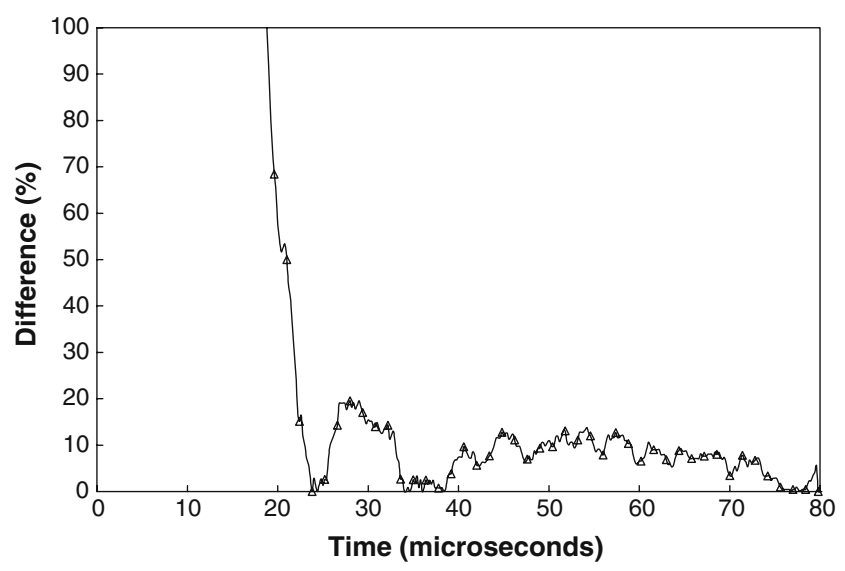

Fig. 6 Percentage difference in stresses at incident and transmitter faces of specimen setups. Several benchmarking experiments were conducted using the neat epoxy and compared with the values for tensile properties of EPONTM 828 reported by Chen et al. [6]. Figure 7 compares the stress-strain response for the quasi-static case $\left(0.002 \mathrm{~s}^{-1}\right)$ as well as the dynamic case $\left(1,350 \mathrm{~s}^{-1}\right)$ for neat epoxy.

For the sake of comparison with the results reported in Ref. [6] the values were converted to true stress and strain using the constant volume assumption. The reported values are approximately $8.5 \%$ true strain at failure for the quasistatic case (for a strain rate of $0.00246 \mathrm{~s}^{-1}$ ) and approximately $8 \%$ true strain at failure for the dynamic case (strain rate of $1,200 \mathrm{~s}^{-1}$ ). The ultimate stresses as seen by the specimens were 70 and $90 \mathrm{MPa}$ for the quasi-static and dynamic cases, respectively. It is commented in Ref. [6] that the test specimens failed in the fillet, and that this may have shadowed the strain rate effects.

The results obtained using the tensile split Hopkinson bar (SHB) apparatus in this work are quite consistent with the ones in Ref. [6] in terms of both trends and stress-strain magnitudes. For this work, the failure strains were slightly lower than those reported [6]; however, in both quasi-static and dynamic experiments specimens failed at similar strains. Also, the failure stresses were in the range of 70 $90 \mathrm{MPa}$. The cure cycle could have played a role in causing the lower failure strains observed in the present work. The specimens tested by in Ref. [6] were cured at room temperature for 7 days, while the specimens in this work were cured at room temperature for 1 day followed by a post cure at elevated temperature.

\section{Experimental Results on Particulate Composites}

Using the SHB apparatus, two sets of experiments were conducted. For each specimen type, at least three quasi-static

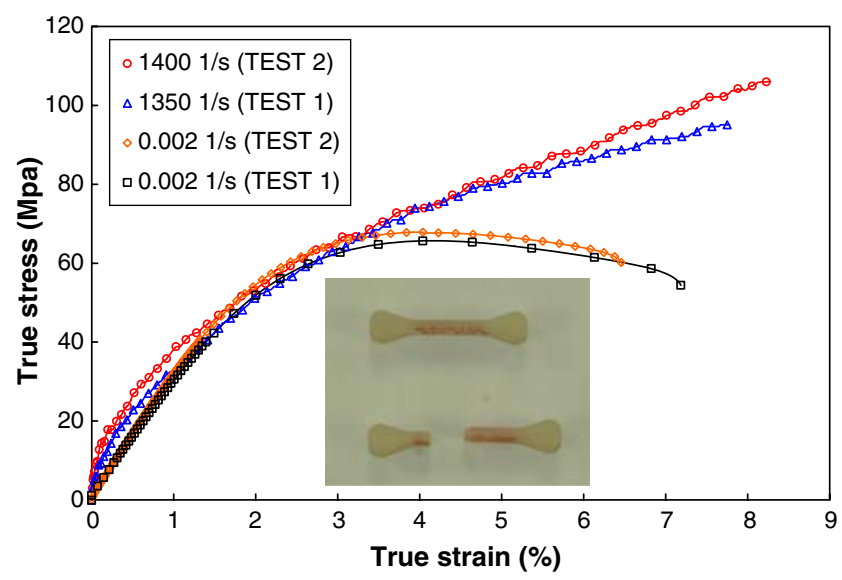

Fig. 7 Quasi-static and dynamic stress-strain response for EPON $828^{\mathrm{TM}}$ epoxy 
Table 1 Properties for glass-filled epoxy with different filler volume fractions ( $25 \mu \mathrm{m}$ diameter particles)

\begin{tabular}{lcccccc}
\hline Specimen \# & $\begin{array}{c}\text { Volume } \\
\text { fraction }(\%)\end{array}$ & $\begin{array}{l}\text { Density } \\
\left(\mathrm{kg} / \mathrm{m}^{3}\right)\end{array}$ & $\begin{array}{l}\text { Longitudinal } \\
\text { wave speed }(\mathrm{m} / \mathrm{s})\end{array}$ & $\begin{array}{l}\text { Shear wave } \\
\text { speed }(\mathrm{m} / \mathrm{s})\end{array}$ & $\begin{array}{l}\text { Elastic modulus, } \\
\text { quasi-static }(\mathrm{GPa})\end{array}$ & $\begin{array}{c}\text { Elastic modulus, } \\
\text { pulse-echo }(\mathrm{GPa})\end{array}$ \\
\hline E0000 & 0 & $1,168 \pm 55$ & $2,458 \pm 47$ & $1,106 \pm 21$ & $3.26 \pm 0.07$ & $3.93 \pm 0.35$ \\
E2510 & 10 & $1,301 \pm 61$ & $2,497 \pm 48$ & $1,141 \pm 22$ & $3.64 \pm 0.04$ & $4.64 \pm 0.42$ \\
E2520 & 20 & $1,434 \pm 67$ & $2,597 \pm 50$ & $1,222 \pm 23$ & $4.64 \pm 0.04$ & $5.82 \pm 0.52$ \\
E2530 & 30 & $1,567 \pm 72$ & $2,764 \pm 53$ & $1,356 \pm 26$ & $5.65 \pm 0.16$ & $7.74 \pm 0.70$
\end{tabular}

and four dynamic tensile tests were conducted. The first round of experiments was conducted to observe the effect that filler particle volume fraction has on stress-strain response. To the knowledge of the authors, the present work is the first to address this at elevated strain rates for filler particles of different volume fractions. The mean diameter of the glass particles for this study was $25 \mu \mathrm{m}$. The quasi-static and dynamic tests were conducted for specimens with $0 \%$, $10 \%, 20 \%$, and $30 \%$ fill by volume. The second round of experiments was conducted to observe the effect of filler particle size on stress-strain response. The filler volume fraction for this study was maintained at $10 \%$. Filler particles of mean diameters $11,25,35$, and $42 \mu \mathrm{m}$ were used.

There are difficulties such as porosity and particle settlement involved in introducing the glass filler particles into the polymer matrix. To minimize porosity, the materials were mixed at an elevated temperature and placed in vacuum as described previously. However, at higher filler volume fractions, it becomes increasingly difficult to cast specimens with low porosity. To decrease the likelihood of particle settling, submicron thickening agents such as CaboSil can be utilized. However, to limit the number of variants, this option was not examined, resulting in a smaller range of allowable particle diameters $(11-42 \mu \mathrm{m})$ to explore.

\section{Filler Volume Fraction Effect on Stress-strain Behavior}

The longitudinal and shear wave speeds were measured using ultrasonic pulse-echo transducers. The wave speeds and specimen densities were then used to find the elastic modulus and Poisson's ratio of each specimen by solving equations:

$C_{\mathrm{L}}=\sqrt{\frac{E(1-v)}{\rho(1+v)(1-2 v)}}$,

$$
C_{\mathrm{S}}=\sqrt{\frac{E}{2 \rho(1+v)}}
$$

simultaneously. In equations (4) and (5), $E$ is elastic modulus, $\rho$ is density, and $\nu$ is Poisson's ratio. $C_{\mathrm{L}}$ and $C_{\mathrm{S}}$ are the measured longitudinal and shear wave speeds. (Due to the unreliable nature of stress-strain data in the early portion of the SHB experiments, the values for elastic modulus found using pulse-echo measurements are used.) The specimen properties are listed in Table 1.

This stiffening effect due to increasing volume fraction of glass particles in the composite has been investigated and is well supported in the literature. Ishai and Cohen [1, 2] and Smith [20] were some of the earlier investigators to examine stress-strain response of glass-filled epoxy composites. The results from quasi-static experiments from the present work are shown in Fig. 8. The addition of the stiffer second phase clearly increases the elastic modulus of the material. This is consistent with trends previously observed in the literature.

Next, in Fig. 9, dynamic stress-strain responses obtained from SHB experiments for various filler volume fraction are shown. Despite being unable to make a direct measurement of the elastic modulus in the dynamic case, the effect of volume fraction on the dynamic stiffness can be seen qualitatively by observing the overall stress-strain responses.

In terms of ultimate stresses, the specimens generally failed at lower values with increased filler volume fractions when tested under dynamic conditions. This is shown in Fig. 10. It is clear that the dynamic ultimate stress values

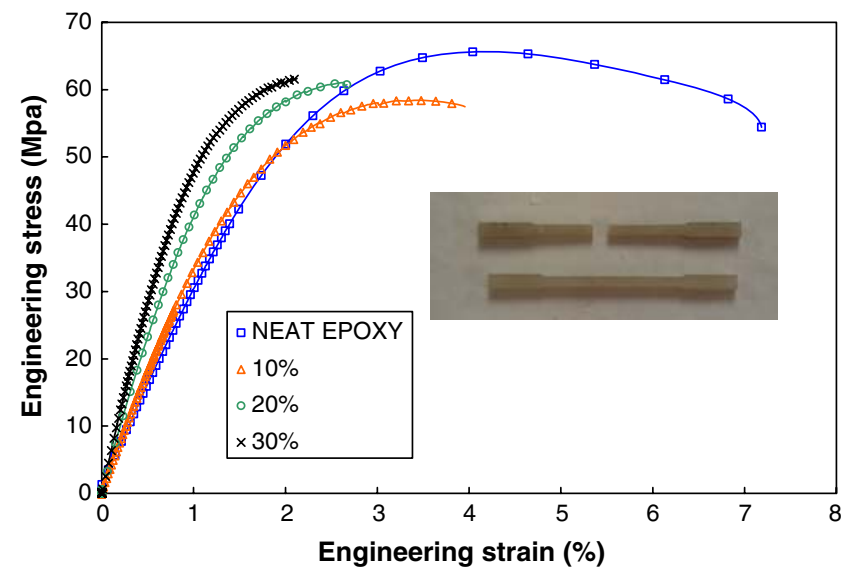

Fig. 8 Typical quasi-static stress-strain response for $25 \mu \mathrm{m}$ glassfilled epoxy with different filler volume fractions (strain rate $\approx$ $0.002 \mathrm{~s}^{-1}$ ) 


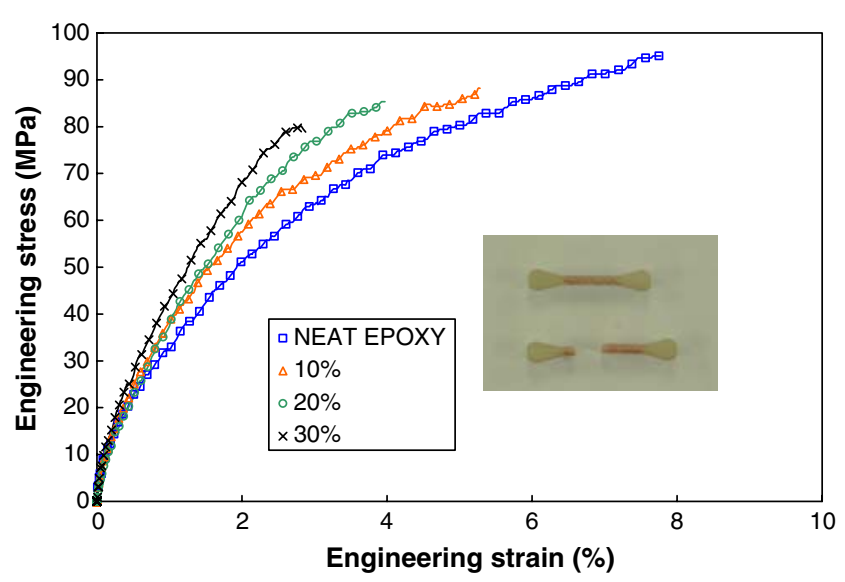

Fig. 9 Typical dynamic stress-strain response for $25 \mu \mathrm{m}$ glass-filled epoxy with different filler volume fractions (strain rate $\approx 1,300 \mathrm{~s}^{-1}$ )

decrease between $0 \%$ and $30 \%$ filler volume fractions. On the other hand, in the quasi-static load cases, within experimental scatter the ultimate stresses remained nearly constant with filler particle volume fraction. In terms of strain rate effect, dynamic ultimate stresses are consistently higher than the quasi-static values in all volume fraction cases. Besides decreasing the ultimate stress under dynamic loading, increasing filler volume fraction also led to a decrease in specimen ductility. In this context, it is worth noting that previous research, particularly that by Ishai and Cohen [1, 2], has shown a general increase in ultimate stress with volume fraction for this type of composite under quasi-static loading conditions as well.

The decrease of ultimate stress with filler volume fraction under dynamic conditions is not clearly understood due to the micromechanical complexities involved. However, interfacial debonding between the particles and the matrix due to propagating stress waves could likely result in

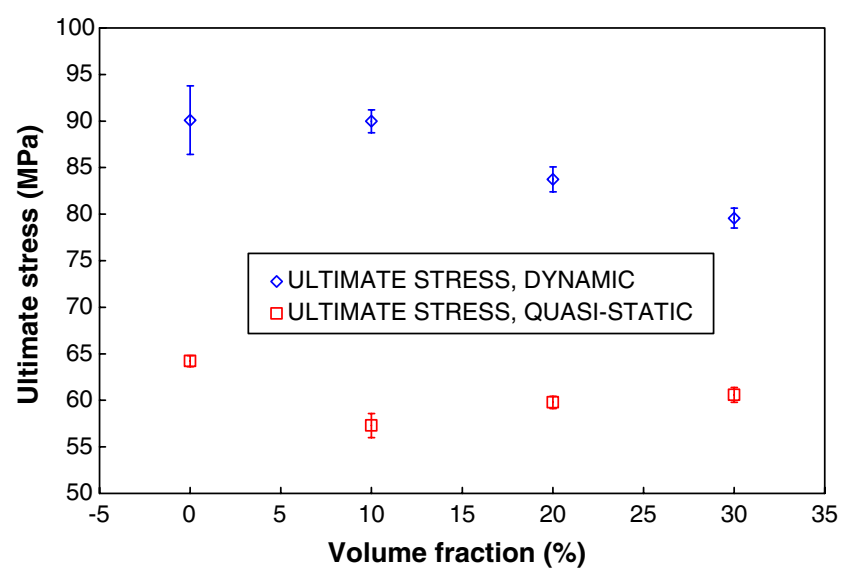

Fig. 10 Ultimate stresses for $25 \mu \mathrm{m}$ glass-filled epoxy with different filler volume fractions the evolution of internal defects during a dynamic loading event. At higher volume fractions, the concentration of such defects is greater and hence lower ultimate stresses may be expected. A second source of the decrease in ultimate stress could be due to the possibility of gas entrapment. At higher filler volume fractions, the mixture becomes much more viscous thus increasing the difficulty of degassing during casting. This could introduce microscopic porosity into the material, hence increasing this progression of internal defects due to the propagating stress wave, therefore, lowering ultimate stress.

For the dynamic experiments, both volume fraction as well as strain rate play a role in the embrittlement of the specimen. It has been demonstrated [1] that at low strain rates (quasi-static) these two factors are independent of each other, but it is possible that at higher strain rates, the effects become coupled. If the two variables were independent of one another, the change in ultimate stress with respect to strain rate, $\frac{\partial \sigma_{y}}{\partial \log [\vec{\varepsilon},}$, should remain constant across the range of volume fractions. However, this quantity changes with different volume fractions by as much as $20 \%$. Such a coupling of the two effects could play a role in causing the decreased ultimate stress with increased volume fraction of the filler.

In general, the specific energy absorbed by each specimen decreased with volume fraction due to the reduction in strain at failure in both the quasi-static and dynamic loading conditions. Specific energy dissipated by test specimens subjected to dynamic loading was consistently higher than the corresponding quasi-static ones over the range of volume fractions studied. These trends are shown in Fig. 11. As the particle volume fraction increases, there is a reduction in the amount of inelastic deformation that occurs. Since a large portion of energy is dissipated during the inelastic regime, the total energy is reduced.

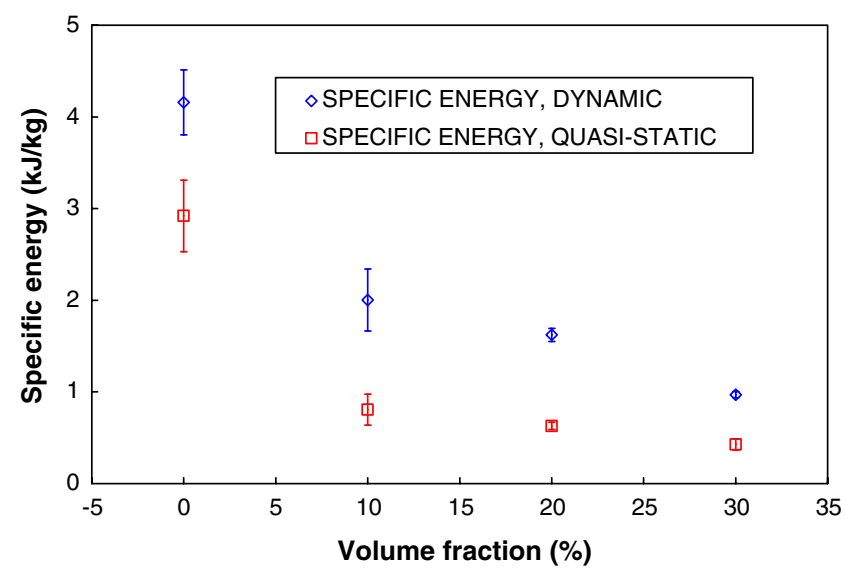

Fig. 11 Specific energy absorption for $25 \mu \mathrm{m}$ glass-filled epoxy with different volume fractions 


\section{Predictions based on micromechanics}

Several models have been proposed to predict elastic properties of composites based on the known properties of the matrix and inclusions. In addition, several investigators have suggested methods to predict failure properties based on empirical, finite element and probabilistic approaches.

The Mori-Tanaka model is commonly used to describe the relationship between elastic modulus and filler volume fraction in heterogeneous material systems. The predictions based on this model, as described by Weng [21], is given by equations (6) and (7) below:

$\kappa=\kappa_{\mathrm{m}}\left(1+\frac{V_{\mathrm{f}}}{\frac{3\left(1-V_{\mathrm{f}}\right) \kappa_{\mathrm{m}}}{3 \kappa_{\mathrm{m}}+4 \mu_{\mathrm{m}}}+\frac{\kappa}{\kappa_{\mathrm{i}}-\kappa_{\mathrm{m}}}}\right)$,

$\mu=\mu_{\mathrm{m}}\left(1+\frac{V_{\mathrm{f}}}{\frac{6\left(1-V_{\mathrm{f}}\right)\left(\kappa_{\mathrm{m}}+2 \mu_{\mathrm{m}}\right)}{5\left(3 \kappa_{\mathrm{m}}+4 \mu_{\mathrm{m}}\right)}+\frac{\mu_{\mathrm{m}}}{\mu_{\mathrm{i}}-\mu_{\mathrm{m}}}}\right)$

where subscripts $\mathrm{m}$ and $\mathrm{i}$ denote the 'matrix' and 'inclusion', respectively. Lame's constants are denoted by $\kappa$ and $\mu$, and $V_{\mathrm{f}}$ denotes volume fraction of the filler. Elastic modulus, $E$, is computed using $E=\frac{9 \kappa \mu}{3 \kappa+\mu}$.

In the present work, values of Young's modulus and Poisson's ratio used to compute the bulk and shear modulus of the glass filler are $69 \mathrm{GPa}$ and 0.2 , respectively. As evidenced in Fig. 12, the lower-bound Mori-Tanaka model predicts the elastic response to filler volume fraction quite well for both the quasi-static values as well as the values from ultrasonic measurements. In some instances the measured values are slightly lower than the prediction, possibly attributed to microscopic porosity unaccounted for in equations (6) and (7).

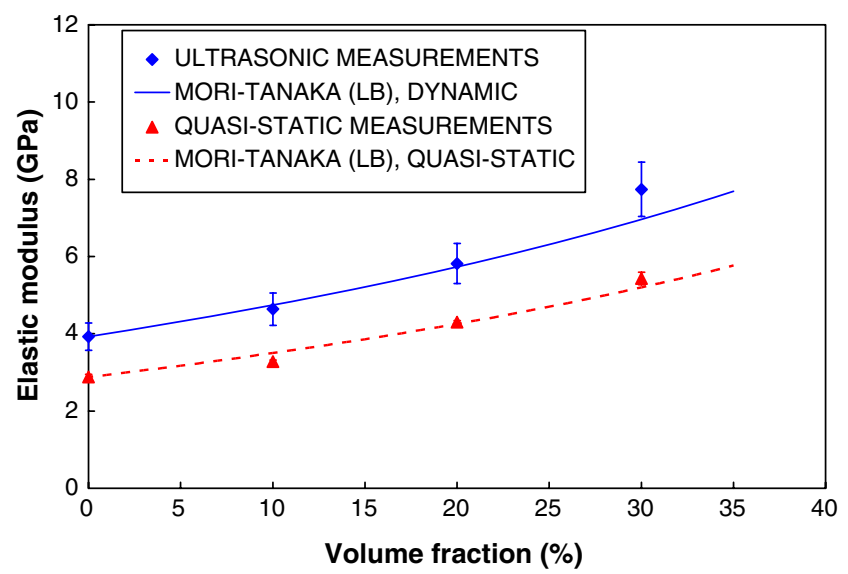

Fig. 12 Comparison of experimental elastic moduli with analytical predictions
In terms of stress, relatively fewer models have been suggested to quantify the effect of filler volume fraction on failure stress. One such model, recommended by Piggott and Leidner [22], assumed that failure stress was dependant on filler volume fraction in a linear sense. They commented that some relationship of the form $\frac{\sigma_{\mathrm{u}}}{\left(\sigma_{\mathrm{u}}\right)_{\mathrm{m}}}=K-b V_{\mathrm{f}}$ was adequate for describing the behavior. In this case, $K$ was a stress concentration factor and $b$ was a constant dependant upon particle-matrix adhesion strength. The negative value suggests that weakly bonded filler lowers $\sigma_{\mathrm{u}}$ of the composite of a known $V_{\mathrm{f}}$. The failure stress of the unfilled matrix is denoted as $\left(\sigma_{\mathrm{u}}\right)_{\mathrm{m}}$ and the failure stress of the composite is denoted as $\sigma_{\mathrm{u}}$. Another model, proposed by Nicolais and Mashelkar [23], argued that a relationship of the form $\frac{\sigma_{\mathrm{u}}}{\left(\sigma_{\mathrm{u}}\right)_{\mathrm{m}}}=1-b V_{\mathrm{f}}^{n}$ was more appropriate. They recommended that positive values of $b$ and values of $n<1$ were sufficient to represent the behavior. Specifically, they suggested that $b=1.21$ and $n=2 / 3$ for glass-filled polymers. Both of these models are predominately empirical in nature. A third model, derived by Schrager [24], took more of a probabilistic approach. In this case, $\frac{\sigma_{\mathrm{u}}}{\left(\sigma_{\mathrm{u}}\right)_{\mathrm{m}}}=e^{-r V_{\mathrm{f}}}$ where $r$ is computed based on the particle diameter, $R$, as well as the interphase distance, $\Delta R$. Schrager considers the interphase distance as the portion of the matrix that is affected by the addition of the fillers due to local stress concentrations. Specifically, $r=\left(v_{\mathrm{i}}+v_{\mathrm{p}}\right) / v_{\mathrm{p}}$ where $v_{\mathrm{i}}=4 \pi(R+\Delta R)^{3} / 3$ and $v_{\mathrm{p}}=4 \pi R^{3} / 3$. Each of these models along with the measured data is shown in Fig. 13.

For the current results, none of these models had outstanding agreement with the experimental values, although the model proposed by Piggot and Leidner [22] could capture the experimental trend for a fitted value of $K=1$ and $b=1 / 2$. For the Schrager model, values of $R=25 \mathrm{e}-6 \mathrm{~m}$ and $\Delta R=5 \mathrm{e}-6 \mathrm{~m}$ produced the results plotted in Fig. 13. These values do make physical sense given the mean particle diameter.

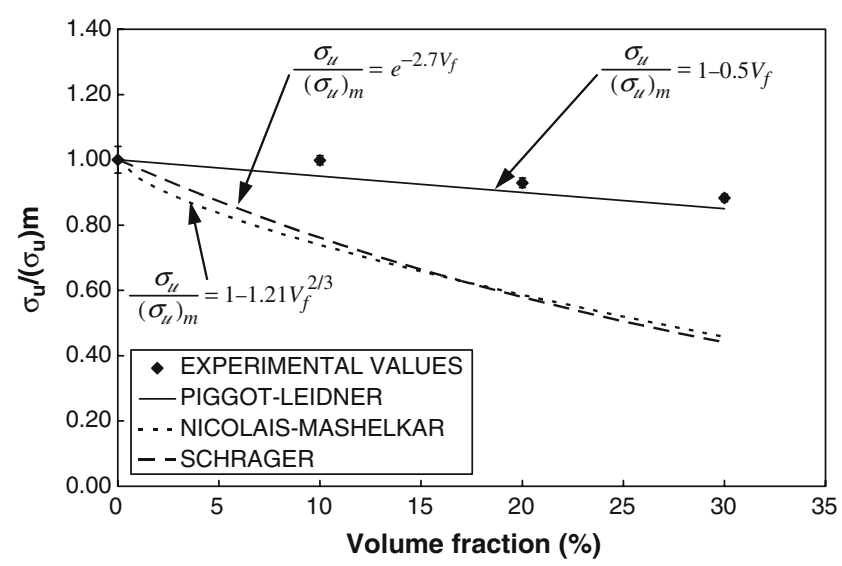

Fig. 13 Comparison of ultimate strength values with previous empirical models 
Table 2 Specimen properties for glass-filled epoxy with various filler particle diameters $(10 \%$ filler volume fraction)

\begin{tabular}{lllll}
\hline $\begin{array}{l}\text { Specimen } \\
\#\end{array}$ & $\begin{array}{l}\text { Mean } \\
\text { particle size } \\
(\mu \mathrm{m})\end{array}$ & $\begin{array}{l}\text { Density } \\
\left(\mathrm{kg} / \mathrm{m}^{3}\right)\end{array}$ & $\begin{array}{l}\text { Longitudinal } \\
\text { wave speed } \\
(\mathrm{m} / \mathrm{s})\end{array}$ & $\begin{array}{l}\text { Shear wave } \\
\text { speed }(\mathrm{m} / \mathrm{s})\end{array}$ \\
\hline E0000 & 0 & $1,168 \pm 48$ & $2,458 \pm 47$ & $1,106 \pm 21$ \\
E1110 & 11 & $1,301 \pm 54$ & $2,497 \pm 48$ & $1,141 \pm 22$ \\
E2510 & 25 & $1,301 \pm 54$ & $2,509 \pm 48$ & $1,157 \pm 22$ \\
E3510 & 35 & $1,301 \pm 54$ & $2,484 \pm 48$ & $1,145 \pm 22$ \\
E4210 & 42 & $1,301 \pm 54$ & $2,502 \pm 48$ & $1,145 \pm 22$ \\
\hline
\end{tabular}

Particle size effect on stress-strain behavior

As previously stated, an investigation of particle size effect was also conducted. Once again, ultrasonic measurements were used along with equations (4) and (5) to obtain the elastic modulus and Poisson's ratio of each specimen. The measured specimen properties are listed in Table 2. The stiffness remains nearly constant for the various particle sizes since the volume fraction is kept constant at $10 \%$. This is evidenced in the stress-strain responses shown in Figs. 14 and 15 for both the quasi-static tests as well as the dynamic ones. For the quasi-static case, stress-strain response for different particle sizes was nearly identical. The largest particle size $(42 \mu \mathrm{m})$ failed at a lower strain than the others; however, the failure for all tests occurred near the grip. It was thus suspected that the lower failure strain was possibly related to the larger particle size in relation to specimen dimensions.

Qualitatively, the dynamic stress-strain responses for the various particle sizes are very similar in terms of stiffness (Figs. 14 and 15). Specimens with particle sizes of 11 and $25 \mu \mathrm{m}$ had almost identical responses. In terms of ultimate stresses [values shown in Fig. 16], there is a non-

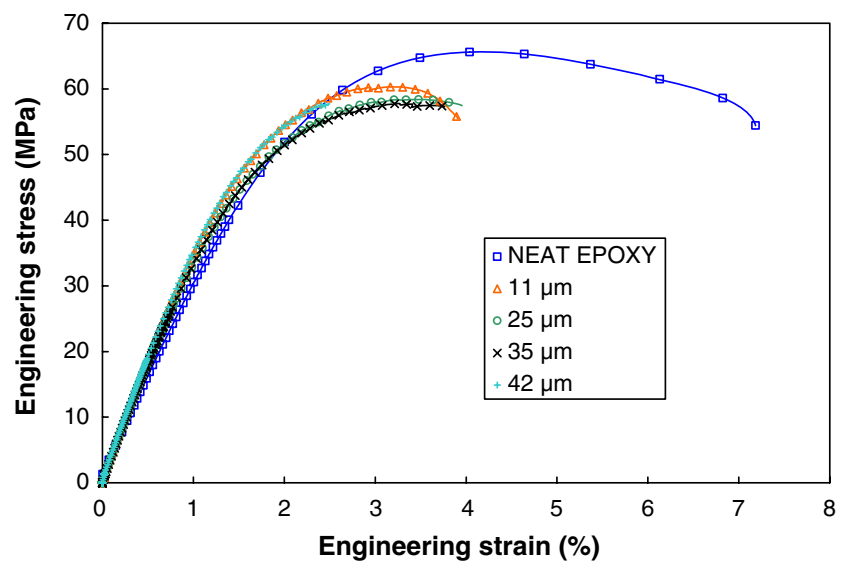

Fig. 14 Typical quasi-static stress-strain response of 10\% volume fraction glass-filled epoxy with different particle sizes (strain rate $\approx$ $\left.0.002 \mathrm{~s}^{-1}\right)$

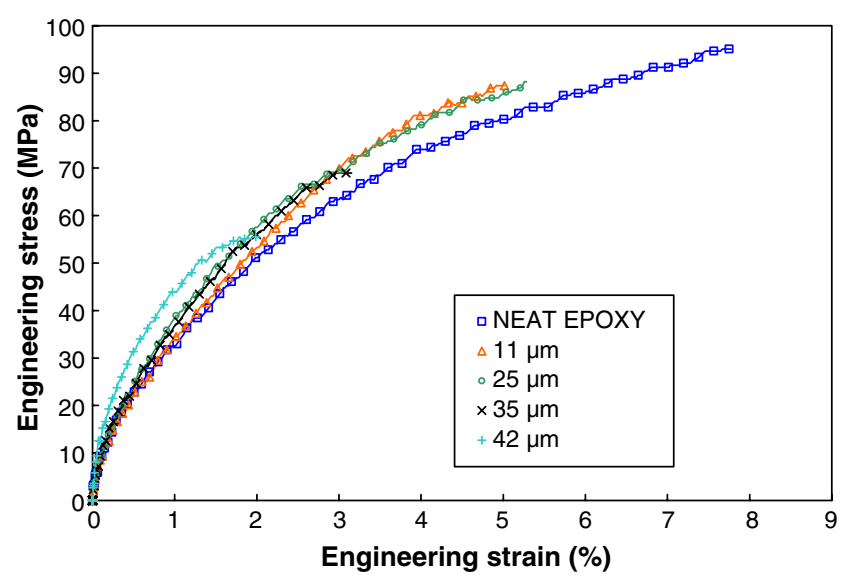

Fig. 15 Typical dynamic stress-strain response of $10 \%$ volume fraction glass-filled epoxy with different particle sizes (strain rate $\approx$ $\left.1,300 \mathrm{~s}^{-1}\right)$

monotonic behavior with respect to particle size. Within the experimental error, both $25-\mu \mathrm{m}$ particle and $11-\mu \mathrm{m}$ particle specimens have the highest strength. The $35-$ and $42-\mu \mathrm{m}$ particle specimens had ultimate stresses that were $22 \%$ and $37 \%$ respectively lower than the $25-\mu \mathrm{m}$ particle specimens. A similar observation was made by Kitey and Tippur [5], where fracture toughness values ranged from $1.86 \mathrm{MPa} \mathrm{m}^{1 / 2}$ for $7 \mu \mathrm{m}$ particles to $2.31 \mathrm{MPa} \mathrm{m}{ }^{1 / 2}$ for $35 \mu \mathrm{m}$, and back to 1.67 MPa m $\mathrm{m}^{1 / 2}$ for $203 \mu \mathrm{m}$ particles. Since dynamic fracture toughness is a more localized measurement than ultimate stress, it can be more sensitive to the effect of filler particle size, thus resulting in a more noticeable non-monotonic response.

However, for this work, the error in the values of ultimate stresses for the 11 - and $25-\mu \mathrm{m}$ specimens overlaps. Also, the ultimate stress showed a small decrease for all particle sizes in the quasi-static case. The only way to be certain is to test a wider range of particle diameters.

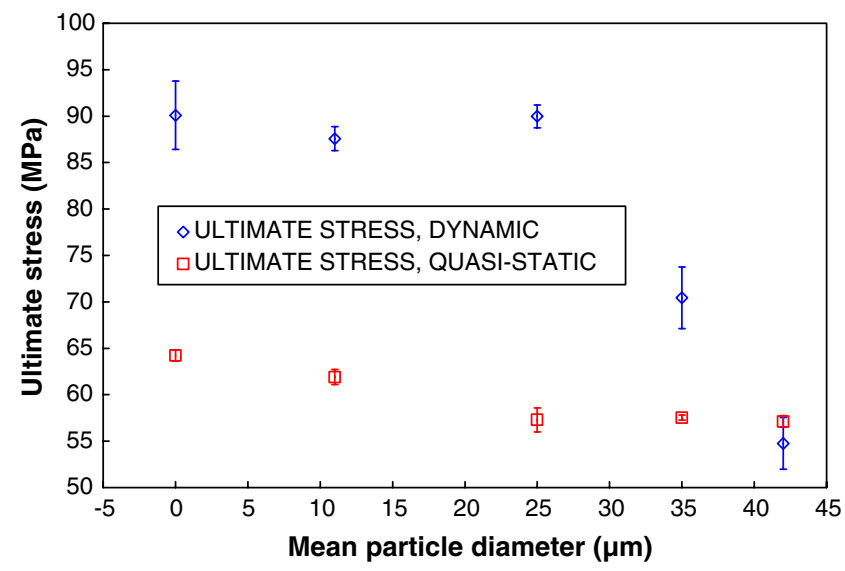

Fig. 16 Particle size effect on ultimate stresses $(10 \%$ filler volume fraction) 


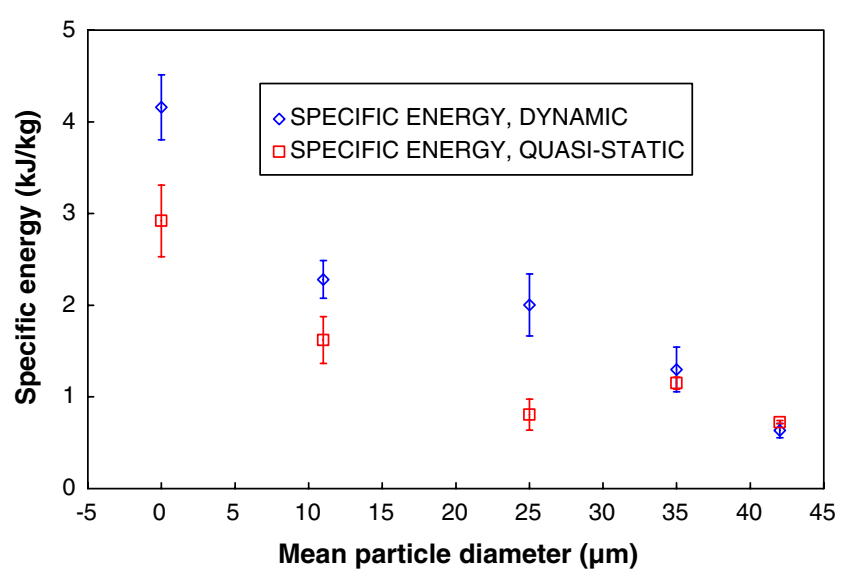

Fig. 17 Specific energy absorption for different particle sizes $(10 \%$ filler volume fraction)

However, in the present work, difficulties were encountered when casting specimens with smaller particles $(7 \mu \mathrm{m})$ and larger particles $(71 \mu \mathrm{m})$. In the $7-\mu \mathrm{m}$ particle case, it was very difficult to prevent particles from coalescing without resorting to additional mechanical (ultrasonic) or chemical steps. In the 71- $\mu \mathrm{m}$ particle case, the particles had a tendency to settle due to the lengthy gel time associated with the epoxy system used in this work. Addition of modifiers to the epoxy system would certainly make it possible to cast a much broader range of particle sizes. However, understanding the influence of modifiers and the associated processing parameters in addition to the effect of particle size was beyond the scope of this work.

As in the study of volume fraction effects discussed previously, specific energy absorption decreases with increasing particle size as shown in Fig. 17. There is evidence of some embrittlement associated with the larger particles, even though all of the specimens contained the same volume fraction. It indicates the presence of additional competing mechanisms causing the difference.

\section{Conclusions}

The effect of filler particle volume fraction and filler particle size effect on tensile stress-strain response at elevated rates of loading was investigated. The materials were tested using a split Hopkinson tensile bar with a unique specimen gripping configuration. Results obtained from the new configuration were compared with values reported in the literature for a commercially available epoxy system. This configuration proved to work quite well for castable materials by drastically reducing the specimen processing time. The specimens were also not subjected to the potential for residual stresses associated with machining or fastening.
The increase in particle volume fraction from $0 \%$ to $30 \%$ led to an increase in material stiffness for both the quasistatic and dynamic load cases. The increase in loading rate contributed to stiffening as well. The specimens had lower ultimate stresses in the high strain rate case for higher volume fractions, whereas the ultimate stresses for the quasistatic case increased, though only modestly, with volume fraction. The ultimate stresses for the dynamic case were consistently higher for all volume fractions, by as much as $25 \%$. The failure strains also showed a monotonic reduction with volume fraction for both quasi-static and dynamic cases. All of these factors also had an embrittling effect on the specimens as evidenced by a monotonic reduction in the specific energy with volume fraction in both static and dynamic cases. The ultimate stress results were also compared with several previous empirical models that were originally proposed based on lower strain-rate behavior.

Stress-strain responses for different particle sizes (11$42 \mu \mathrm{m})$ were also obtained. The particle size did not affect the elastic properties in general. Further, in the quasi-static case, the effect of particle size on failure stress was marginal over the range of particle sizes examined. In the dynamic cases, however, larger particles caused a reduction in the ultimate stress. The failure strains also decreased with particle size under both static and dynamic conditions. These in turn produced a continuous reduction of specific energy in both the cases.

Acknowledgements Partial support for this research through grants NASA-NNL04AA18A, NASA-NNG05GE80H and NSFCMS-0509060 is greatly appreciated by the authors.

\section{Appendix A}

Grip and Specimen Shape Design

Specimen Grip Design: A dovetail shaped specimen gripping mechanism was chosen in an effort to minimize the attenuation that can occur in more complex attachment configurations such as specimens with threaded ends, clamps with fasteners, etc. Finite element analysis was used to arrive at a specific shape that would allow the bars to be used repeatedly without damage. The details of this process are outlined in the following.

A generic dovetail shape is shown in Fig. 18 along with the complementary dogbone specimen. There are several features that require attention in this particular arrangement. Some of these include (a) the dovetail width, (b) the dovetail length, (c) the angle between the dovetail and the axis of the bar, and (d) the filet radius.

An initial geometry was selected, machined and tested in the actual setup. For this initial specimen-bar interface 


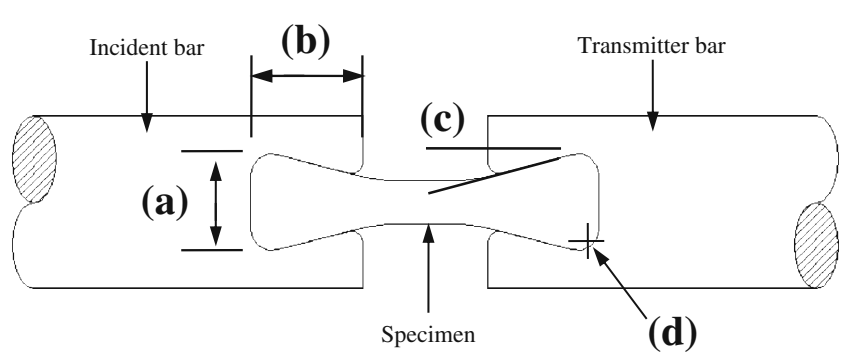

Fig. 18 Generalized dovetail configuration showing features of interest

geometry the dovetail in the incident bar end failed. A closer look at this geometry with finite element analysis revealed that the stresses produced in the aluminum grips during the experiment due to the stress concentration were in excess of the failure stress for the 7075-T6 aluminum being used. Thus, this geometry was used as a benchmark for refining the specimen-bar interface shape such that the tensile testing would not result in failure of the grip region of the incident bar.

The finite element model used for this purpose consisted of two parts, the specimen and the incident bar ends. The geometry was modeled in Solid Edge ${ }^{\circledR}$ graphics tool and

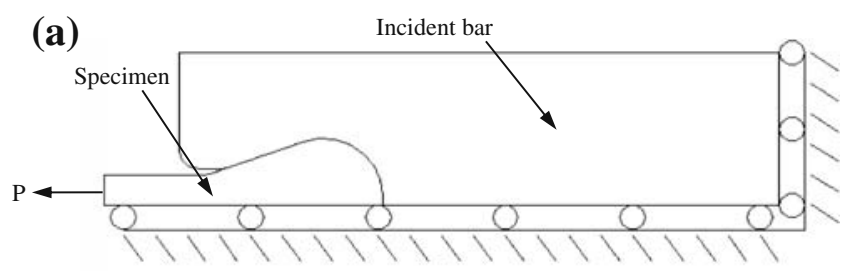

(b)

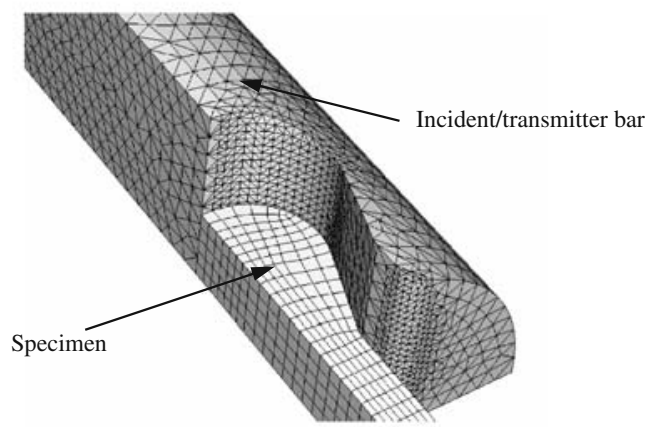

(c)

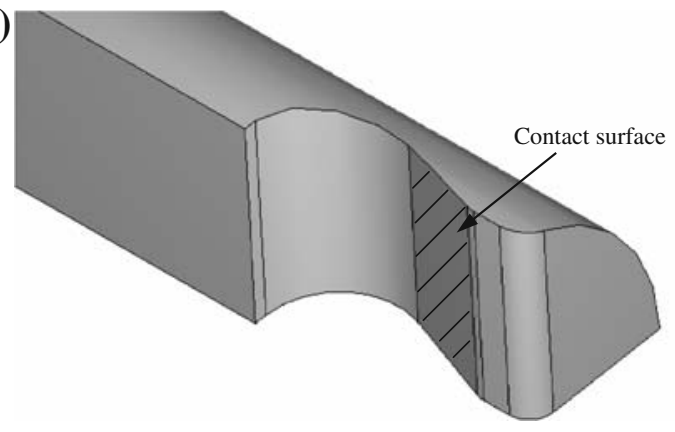

Fig. 19 (a) Loads and boundary conditions for dovetail model, (b) finite element model of dovetail grip, (c) surface of contact enforcement (a)

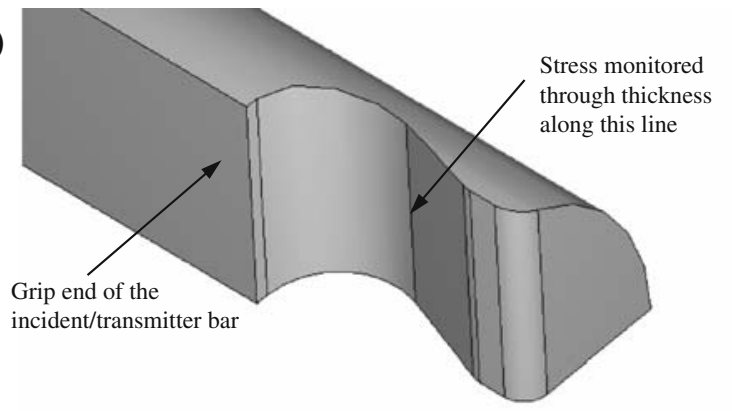

(b)

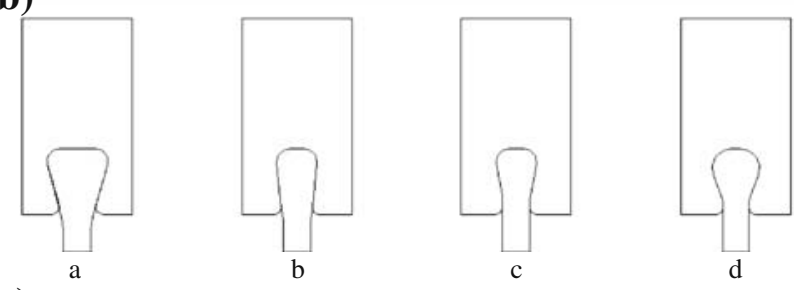

(c)

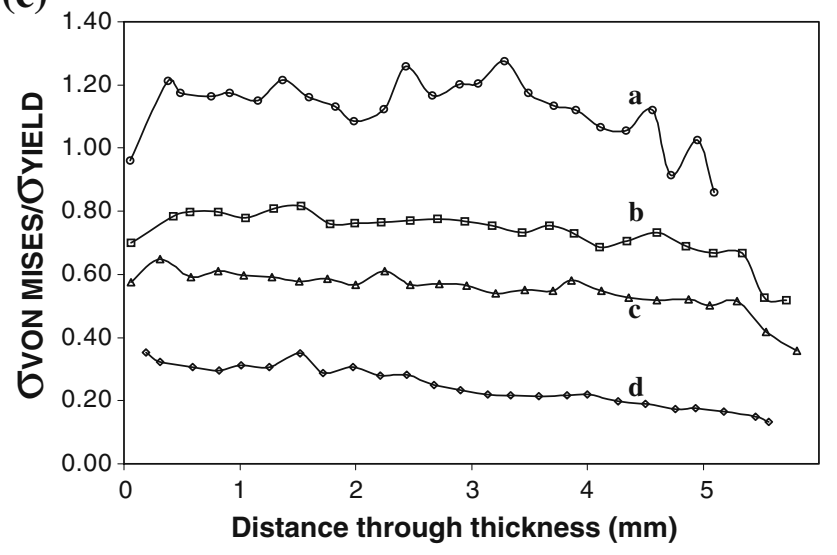

Fig. 20 (a) Line of interest for stresses, (b) geometries of interest, (c) stress through the thickness for different geometries

converted into an IGES (initial graphics exchange specification) format. This neutral file format was imported directly into $\mathrm{ABAQUS}{ }^{\circledR}$ structural analysis environment. The two parts were then discretized independently and merged together as an assembly. Due to the complex geometry of the bar end, four-noded linear tetrahedral elements (C3D4 in ABAQUS ${ }^{\circledR}$ ) were used for the mesh. The specimen itself was meshed using eight-noded linear brick elements (C3D8R in ABAQUS $\left.{ }^{\circledR}\right)$. Quarter symmetry

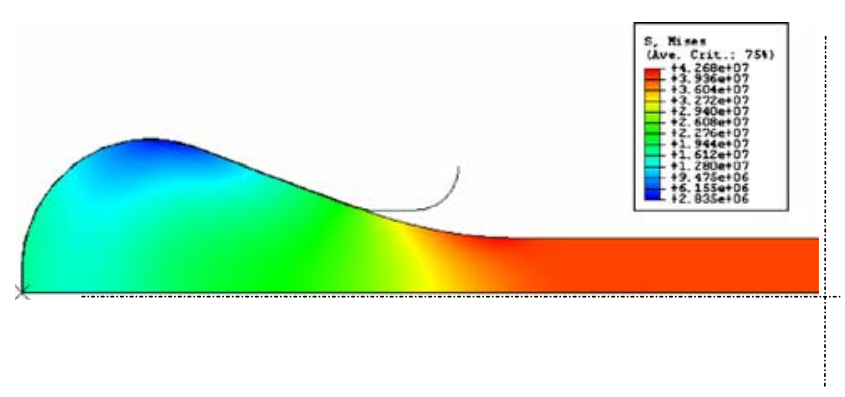

Fig. 21 Typical specimen stress distribution 
of the configuration was exploited to reduce the size of the model. This allowed the use of a much denser mesh for improving the accuracy of results. About 20,000 elements were used to discretize the incident bar end, and about 1,000 elements were used for the specimen. Figure 19(a) shows the loads and boundary conditions used in the model. The mesh is shown in Fig. 19(b).

Contact elements were used along the interface between the bar and specimen on the hatched surface shown in Fig. 19(c). The contact was formulated for both the surface normal and tangential directions. The constitutive law for contact elements included a linear stress-strain behavior in the direction normal to the surface with a stiffness of approximately ten times the stiffness of the aluminum grip. The aluminum surface was chosen as the master surface. In the direction tangential to the surface, the friction between the aluminum grip (master surface) and specimen end (slave surface) was also accounted for using a stiffness (penalty) method. In this method, a certain amount of shear stress is carried across the interface between the master and slave surfaces. The shear stress is directly proportional to the normal load between the surfaces. This allowed for the estimation of the friction during the loading event. The end of the bar was constrained from translation in the horizontal direction, and a uniform pressure was applied on the end surface of the specimen as shown in Fig. 19(a).

The stresses through the thickness at the location of the least cross-sectional area of the grip (Fig. 20) were the primary output quantity of interest. Designing for a minimal stress ensures that the bar end will endure repetitive loading of the grips. Twelve iterations of the design were explored with the FE model. The particular parameters being studied included the angle of the dovetail, the maximum width of the dovetail, and the length the dovetail extends into the incident bar. The initial (a) and final (d) geometries that were analyzed are shown in Fig. 20(b). Also shown are two of the intermediate geometries ( $b$ and $c$ ).

The plots in Fig. 20(c) correspond to the normalized von-Mises stresses along the line shown in Fig. 20(a). The origin of the plot corresponds to the mid-plane of the cylindrical rod. As can be seen, iteration (a) exceeded the yield strength of the aluminum by $20 \%$ and iteration (d) of the dovetail design had significantly lower stresses.

Specimen Stress Distribution: For tensile specimens, it is necessary that the gage section has a uniform stress distribution, and that there are no obvious stress concentrations. A plane stress finite element analysis was completed to verify this. The finite element model consisted of the desired dogbone geometry registered against an analytically rigid surface. Since aluminum is essentially rigid in comparison to the polymer specimen, an analytically rigid surface could be used instead of a meshed deformable body, thus simplifying the model. Also, quarter symmetry was invoked. The mesh consisted of eight-noded biquadrilateral plane stress elements (CPS8R in ABAQUS $\left.{ }^{\circledR}\right)$. The stress distribution contoured for von Mises stresses for an imposed stress of $40 \mathrm{MPa}$ is shown in Fig. 21. The uniformity of von-Mises stresses in the gage section of the specimen is clearly evident.

\section{References}

1. Ishai O, Cohen LJ (1967) Elastic properties of filled and porous epoxy composites. Int J Mech Sci 9:539-546. doi:10.1016/00207403(67)90053-7.

2. Ishai O, Cohen LJ (1968) Effect of fillers and voids on compressive yield of epoxy composites. J Compos Mater 2:302315. doi:10.1177/002199836800200303.

3. Spanoudakis J, Young RJ (1984) Crack propagation in a glass particle-filled epoxy resin. Part 1. Effect of particle volume fraction and size. J Mater Sci 19:473-486. doi:10.1007/ BF02403234.

4. Nakamura Y, Yamaguchi M (1992) Effects of particle size on the fracture toughness of epoxy resin filled spherical silica. Polymer 3316:3415-3426. doi:10.1016/0032-3861(92)91099-N.

5. Kitey R, Tippur HV (2005) Dynamic crack growth in particulate bimaterials having discrete and diffuse interfaces: role of microstructure. Eng Fract Mech 72:2721-2743. doi:10.1016/j. engfracmech.2005.07.006.

6. Chen W, Lu F, Cheng M (2002) Tension and compression tests of two polymers under quasistatic and dynamic loading. Polym Test 21:113-121. doi:10.1016/S0142-9418(01)00055-1.

7. Song B, Chen W, Yanagita T, Frew DJ (2005) Temperature effects on dynamic compressive behavior of an epoxy syntactic foam. Compos Struct 67:289-298. doi:10.1016/j.compstruct.2004.07.012.

8. Song B, Chen W, Yanagita T, Frew DJ (2005) Confinement effects on the dynamic compressive properties of an epoxy syntactic foam. Compos Struct 67:279-287. doi:10.1016/j.compstruct.2004.07.011.

9. Gray GT III, Blumenthal WR, Trujillo CP, Carpenter RW II (1997) Influence of temperature and strain rate on the mechanical behavior of Adiprene L-100. J Phys IV France 07:C3-523-C3528.

10. Hopkinson B (1914) A method of measuring the pressure produced in the detonation of high explosives or by the impact of bullets. Philos Trans R Soc Lond, A Contain Pap Math Phys Character 213:437-456. doi:10.1098/rsta.1914.0010.

11. Kolsky H (1949) An investigation of the mechanical properties of materials at very high rates of strain. Proc Phys Soc B 62:676700. doi:10.1088/0370-1301/62/11/302.

12. Lindholm US, Yeakley LM (1968) High strain-rate testing: tension and compression. Exp Mech 8:1-9. doi:10.1007/BF02326244.

13. Nicholas $\mathrm{T}$ (1981) Tensile testing of materials at high rates of strain. Exp Mech 21:177-185. doi:10.1007/BF02326644.

14. Staab GH, Gilat A (1991) A direct-tension split Hopkinson bar for high strain-rate testing. Exp Mech 31:232-235. doi:10.1007/ BF02326065.

15. Ogawa K (1984) Impact-tension compression test by using a split-Hopkinson bar. Exp Mech 24:81-85. doi:10.1007/ BF02324987.

16. Huh H, Kang WJ, Han SS (2002) A tension split Hopkinson bar for investigating the dynamic behavior of sheet metals. Exp Mech 42:8-17. doi:10.1007/BF02411046. 
17. Mohr D, Gary G (2007) M-Shaped specimen for the high-strain rate tensile testing using a split Hopkinson pressure bar apparatus. Exp Mech 47:681-692. doi:10.1007/s11340-007-9035-y.

18. Owens AT (2007) Development of a tensile split Hopkinson bar for testing stress-strain response of particulate composites under high rates of loading. M.S. Thesis, Auburn University

19. Gray GT (2000) Classic split Hopkinson bar testing. ASM mechanical testing and evaluation handbook. ASM, Pennsylvania, 8:pp 488-496.

20. Smith JC (1976) The elastic constants of a particulate-filled glassy polymer: comparison of experimental values with theoretical predictions. Polym Eng Sci 16:394-399. doi:10.1002/pen.760160603.
21. Weng GJ (1984) Some elastic properties of reinforced solids, with special reference to isotropic ones containing spherical inclusions. Int J Eng Sci 227:845-856. doi:10.1016/0020-7225(84)90033-8.

22. Piggott MR, Leidner J (1974) Misconceptions about filled polymers. J Appl Polym Sci 18:1619-1623. doi:10.1002/ app.1974.070180604.

23. Nicolais L, Mashalkar R (1976) The strength of polymeric composites containing spherical fillers. J Appl Polym Sci 20:561-563. doi:10.1002/app.1976.070200226.

24. Schrager M (1978) The effect of spherical inclusions on the ultimate strength of polymer composites. J Appl Polym Sci 22:2379-2381. doi:10.1002/app.1978.070220826. 